MATEC Web of Conferences 53, 01053 (2016)

DOI: $10.1051 /$ matecconf $/ 20165301053$

(C) Owned by the authors, published by EDP Sciences, 2016

\title{
Causes of formation of cracks in the outer masonry of multilayer walls in the zone interwindow belts and partition
}

\author{
Sergey Zimin ${ }^{1}$, Raushan Alzhanova ${ }^{1, a}$, Vadim Litovchenko, ${ }^{1, b}$ \\ ${ }^{1}$ Peter the Great St.Petersburg Polytechnic University, 29 Polytechnicheskaya st., St.Petersburg, 195251, Russian \\ Federation
}

\begin{abstract}
This article examine the causes of crack formation in the exterior layer multilayer enclosing structures, on early terms of operation (from 3 to 5 years). The problem is investigated on a concrete example of the existing residential building to St. Petersburg. We explore the cracks in the zone interwindow belts and partition. For explore this question used methods such as: analysis of the experience, visual inspection, the experimental methods in laboratories, numerical modeling in the software package ANSYS. As a result of visual examination of sediment soils are not detected. According to the results tests of a selected samples bricklaying, compliance of its durability to existing rules - is defined. Identified a number of causes of crack formation. Also, a number of recommendations is developed for the design, to avoid similar problems on early terms of operation.
\end{abstract}

\section{Introduction}

Currently, in the Russian Federation is actively building constructed using multilayer structures. Because of search of economic options of the protecting designs with the increased heat transfer resistance. Technology sandwich structures approached for this role better than others.

This type of walling consists of the following layers:

- bearing structure - it can be made of brick, reinforced concrete, aerocrete blocks, etc.;

- insulation - is not regulated, taken depending on the heat engineering calculation;

- a obverse layer - facing brick.

However, this technology was borrowed from European developers, but not adapted to Russian conditions and design methods. Over a short period of time (three to five years) after commissioning, began to arise problems such as cracks in the zone interwindow belts and piers in the obverse layer (bricklaying) and to moisture ingress.

In a consequence of cyclic freezing and thawing of moisture in cracks, they start expanding and finally fragments of a brick and/or a laying collapse. In turn, this leads to the ingress of moisture on the insulation to deteriorate its thermal insulation properties.

Premature repair which is expensive, big flow of complaints, loss of cost of apartments in houses with collapses, damage of an aesthetic look, etc. All these effects, after which in some regions of the Russian Federation, it was decided to prohibit the use of this technology.

\footnotetext{
${ }^{\text {a }}$ Corresponding author : alzhanova03@gmail.com

${ }^{\mathrm{b}}$ Corresponding author : litovchenko.v93@gmail.com
} 
With regard to existing differences our climate from the European, in the domestic housing construction should be more stringent requirements for the material and the design method of an obverse layer [1].

Great contribution to the study of bricks made by Russian scientists M.K. Ischuk [2-11].

Just research the problem have dealt with foreign scientists, such as K.D. Beysli [20], V. Jager, G. Pfeiffer [21], M.E. Phillips, T.A. Montagu [22] - who wrote many works to anchor system in the lining. N.A. Romani [23] was engaged in research pre intense designs in the lining. G. Simudik, A.V. Paige [24] research the development of cracks and crack resistance in the masonry.

N.P. Umnyakova conducted a research about the durability of sandwich walls lined with bricks. Her work explores the causes of the destruction of the sandwich construction of exterior walls with an effective insulation.

Also a great contribution to the explore of the problem made the following researchers: Prof. R.B. Orlovich [12,13], a graduate student N.M. Rubtsov [13], a graduate student S.S. Zimin [12-14], the purpose of their study was to determine the bearing capacity and deformability of the anchoring of the compounds used in the building envelope. They conducted laboratory experiments which resulted in the following conclusions:

1. The bearing ability of anchors pull-out is almost identical to layings of voidness and corpulent bricks in case of use of solutions of bigger brand. At the smaller durability mortar joints of seams characteristics of anchors have paramount value: flexibility, diameter and roughness of a surface.

2. Increased strength and rigidity of anchor links does not guarantee the ability to increase their anchors.

3. Section anchors should be chosen in such a way that their increase is not destroyed mortar joints, while at the same time reducing the gap did not occur from stretching. [13]

Application in the obverse layer of a hollow bricks/stone high voidness, but not corpulent, or a brick/stone with small voidness (at their identical frost resistance), can adversely affect the strength of brickwork. For the combined laying with a relatively thick obverse layer, this fact largely relates to the outside (obverse) exterior tier, which is directly contacting to the atmospheric environment (in given to the combined obverse laying exterior tier it is executed from a brick by voidness of $40 \%$ ). Voidness brick is a kind of structure formed from intersecting two directions thin walls, break the connection between them is relatively easy, which is especially affected:

- at local action of loading;

- at action of loading perpendicular to voids (to thin partitions between them);

- at alternate freezing-thawing of a brick, in the state sated with moisture (water when freezing increases in volume, presses on walls of a time and destroying them, leads to destruction and reduction of durability of a brick). Under adverse conditions when filling with moisture of emptiness (for example, at condensate loss; at active passing of steam through an external wall; through cracks, etc.), water when freezing presses, except walls of a time, on walls of emptiness that leads to the progressing destruction of a brick and, as a result, - layings.

Here it is worth noting that the project is put into the brand of frost resistance of brick characterizes its ability to withstand alternate freezing-thawing, when the latter, as well as moisture saturation brick, wear volume character. In the real conditions atmospheric moisture exposed to outer bulkhead voidness bricks (deep inside the walls of it does not penetrate because of the direction the partial pressure "from inside the building to the outside"). Effects of negative and positive temperatures more susceptible to the same outer bulkhead brick (deep wall temperature aligned). All this leads to emergence of tangent tension $\tau \_y$, on border of an external bulkhead with intervoid (under adverse conditions there is an office of an external bulkhead from intervoid).

In most projects, fixing the outer layer of laying carried to the inner layers or reinforced concrete frame with flexible connections.

The following are the most common errors when the device flexible linkages that have led or may lead after some time for emergencies:

- insufficient corrosion resistance;

- excessive pliability of the plane of the wall; 
- excessive shear stiffness;

- unsatisfactory anchoring the laying obverse and internal layers;

- large distance between connections.

Connection should be rigid enough when working out of the plane of the wall.

The distance between connection in many projects is appointed without any justification. During the construction of the distance between communications and the places of their binding specified in the project on many of the buildings surveyed are not met. [8]

Despite the large amount of work on this subject, the question of how to prevent the formation of cracks at the design stage is not solved.

\section{Research objective}

The purpose of this work is identification of the reasons of formation of damages (cracks) of a obverse layer of external walls to zones of interwindow belts and piers, and also a number of recommendations about design for prevention of formation of cracks is developed.

It will cause the acceptance of all the provisions of tests' ways. Some tests for determination the fire safety's properties of construction materials are similar according to the Russian and European standards. The European system of standardization has the much wider range of test methods for determining the fire safety's properties of construction materials which have no analogues in Russian regulations (table 3 ). The following table compares the roofing materials of different manufacturers. In connection with this direct correlation between the European and Russian parameters is difficult.

The objectives of the work are:

1. Conduct a visual inspection of the exterior walls of the building.

2. Identify the structural features of the building, including outer walls.

3. Conduct a local autopsies and sensing external walls with subsequent analysis of their design decisions, as well as pairing conditions to the supporting structure of the building.

4. Collect samples of brick and mortar of the laying obverse layer, to conduct laboratory tests to determine the mechanical properties of laying.

5. Perform simulation of fragments of the walls and supporting structures.

6 . As a result of the survey and calculations to identify the causes of cracking.

To issue recommendations for prevention of damage at the design stage.

\section{Object of research}

Object of research is the residential building to the address St. Petersburg, Kultury Ave., 19, the case 3 .

\section{Inspection of a residential building}

Visual and constructive examination of external walls of object of research was conducted. With the application of sensing and local autopsies exterior walls.

\section{Description of object of research}

The object of the survey is a residential building (Figure 1), constructed and commissioned in 2009.

The building consists of three sections different storey, separated by expansion joints.

The constructive scheme of building frameless; the load-bearing structure made of reinforced concrete and are mostly walls, and matching them with plates of overlappings.

Elbow, arranged around the perimeter of the building, constructively formed internal transverse reinforced concrete walls; in places where the transverse wall are not provided - reinforced concrete 
columns (plates of overlapping are monolithic interfaced with columns of beamless option). As the transverse walls and columns arranged between aerated concrete laying, forming elbow are thereby inner layer outer end walls formed from facades of the Z- and P-shaped portions.

Plates of the balconies/loggias noted above are constructive continuation of interfloor plates of overlappings.

External walls of the building - multilayered (a detailed description of the external walls and their pairing with reinforced concrete structures, including plates, is presented in section 5.2).

Interior walls are made of aerated concrete. Blocks of elevator shafts are made of precast reinforced concrete. Ventilation units - precast reinforced concrete, arranged on the entire height of the building with the output of gases, vapours, etc. outward directly through the coating.

The foundations of the building - pile; piles unite a tape grillage.

To determine if uneven sediment of the building foundations and understanding the distribution pattern of defects and damage to building structures of the building as a whole - a general inspection of the building from the inside out. Based on the results of the inspection of the damage in the form of typical cracks indicating a substantial residue of irregular foundations, while inspecting the premises of the basement and underground parking, technical floor, rooms of ladder and lift unit, as well as sample dwellings - have been discovered.

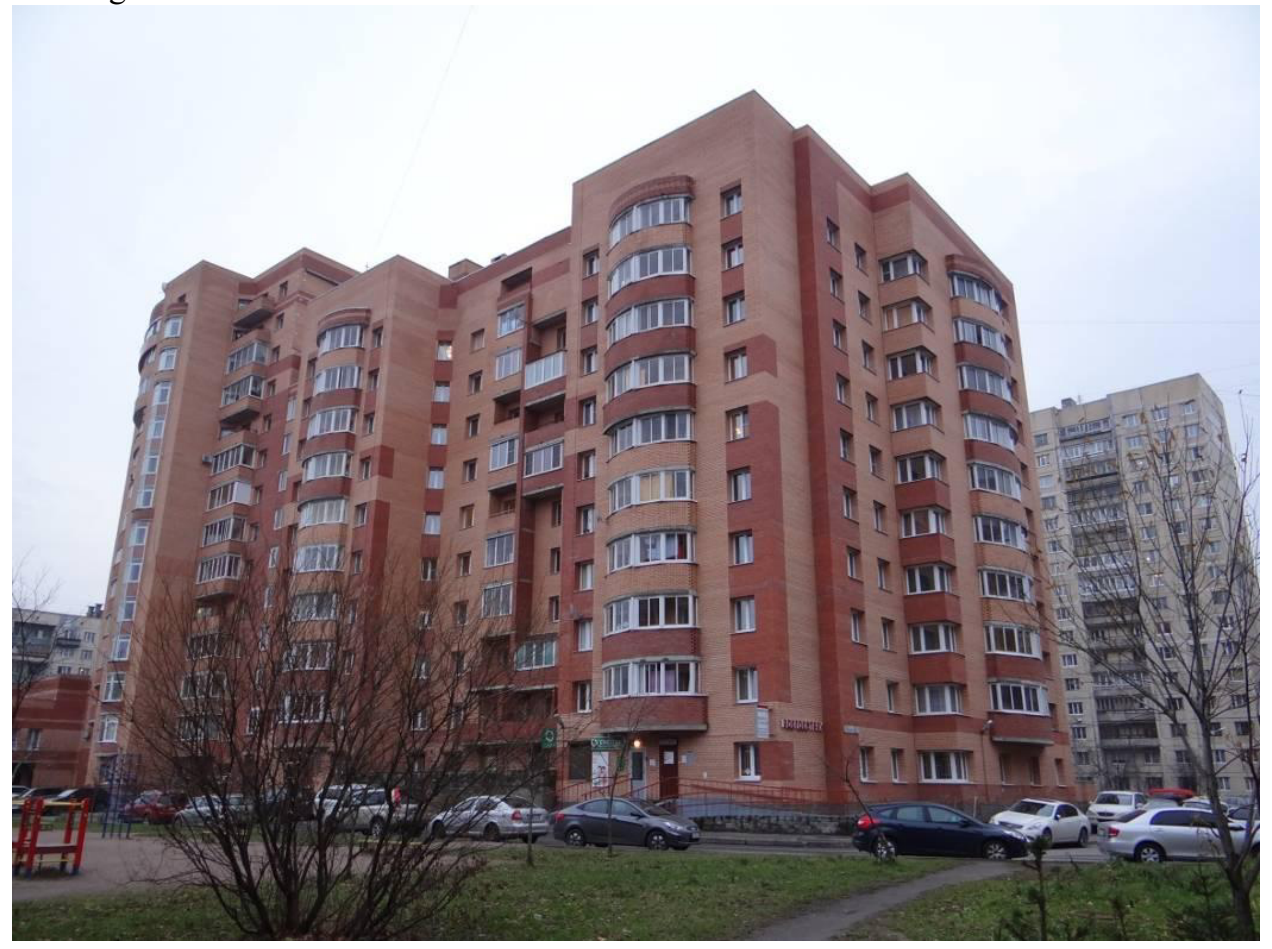

Figure 1. General view of the building

\section{Pair of external walls with reinforced concrete structures}

Determining the actual composition and structural features of the outer walls of the building is made on the basis of the results of autopsies and local sensing obverse layer, followed by a comparison of the actual design decisions. Also, the analysis of constructive solutions of exterior walls was carried out visually from the balconies / loggias and internal rooms. 

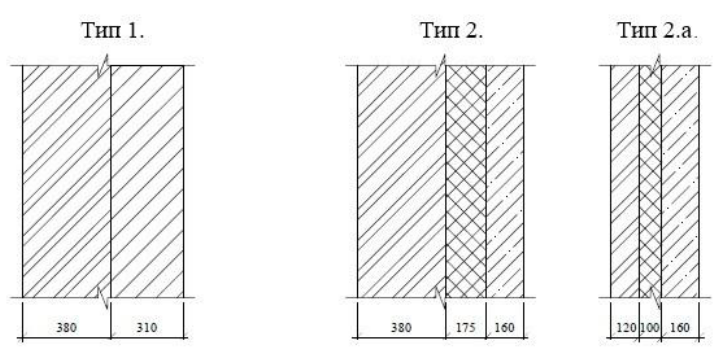

Тип 3 (комбнннрованный).
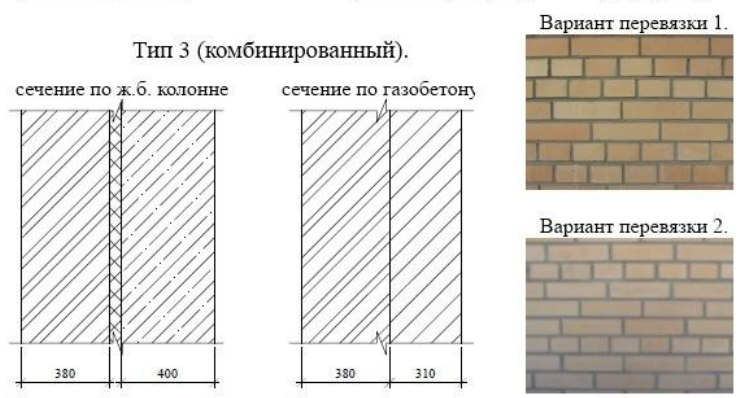

Вариант перевязки 2.

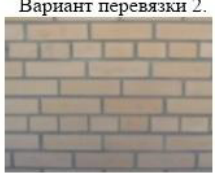

Figure 2. The decision on the external walls

There are the following types of external walls (Figure 2), differing primarily on the composition of the inner layer (outer (obverse) layer is made of a single solution for all types of walls):

Type 1. The outer walls of the rectilinear sections, i.e. sections, going along the facades - double layer: inner layer is presented laying of aerated concrete blocks with a thickness $310 \mathrm{~mm}$, external (obverse) - combined masonry thickness of $380 \mathrm{~mm}$ (decisions laying of an obverse layer, see below).

Type 2. Outside end walls of Z-and P-shaped sections formed by internal cross-walls - three-ply: the inner layer of reinforced concrete thick wall represented $160 \mathrm{~mm}$, external (obverse) - combined masonry thickness of $380 \mathrm{~mm}$ (decisions laying of an obverse layer, see below). Between the internal and obverse layers provides a layer of insulation from min $175 \mathrm{~mm}$ mineral wool.

Type 3 or combined. Outside end walls of Z-and P-shaped sections formed by the inner columns double layer: inner layer is represented by two reinforced concrete columnsm, forming an end face and the laying from aerated concrete blocks arranged between columns. Between the columns and an obverse layer provides insulation.

The inner layer is presented laying of aerated concrete blocks of thickness $380 \mathrm{~mm}$ (types 1, 3) is made with floor-by-floor support on a reinforced concrete plates of overlappings (overhang layer of plates is not provided) and is arranged between the internal transverse reinforced concrete walls (Type 1) or columns (type 3 ). The deformation seam between plate of overlappings, columns, cross-walls, on the one hand, laying or aerated concrete - the other, is not provided. Thus, the inner layer included in the total work support structures.

The inner layers provided reinforced concrete walls with a thickness of $160 \mathrm{~mm}$ (type 2, 2.a), as the main load-bearing structures of the building, performed at full height with support (pairing) on a base grillage. Between the end walls and columns on one side and a obverse layer - on the other hand, there is provides insulation.

By the nature of the work it is possible to distinguish two kinds of an obverse layer depending on whether or not foreseen at sites of facades, representing this view, balconies/loggias:

Type 1 is typical for areas of facades, where there is provided a device of balconies / loggias. This type of an obverse layer can be described as layer arranged on the entire height of the building and connected to the inner layers of aerated concrete and reinforced concrete with flexible links submitted by braces, studs and t. $\mathrm{p}$.

Type 2 is characterized by areas of facades, where balconies/loggias device (section 5.1 stated that balcony plates are the constructive continuation of interfloor overlappings slabs that are going 
outwards, as if "cut" obverse layer). An obverse layer of this type in relation to balkonnym plates can be described as follows:

- plate, "cutting" an obverse layer share his height into separate sections with a height equal to the distance between the plates;

- lack of horizontal deformation seam between a plate and a laying of an obverse layer;

- the floor-by-floor jamming of a laying between plates (or plates in a laying) allows you to talk about the association of individual sections in a single obverse layer, wherein the reinforced concrete plates are the kind of rigid links connecting the obverse layer of the building.

In addition to the above, it is worth mentioning:

- two variants of bandaging of a laying of an obverse layer (Figure 2); and consistency in their application is missing, that provokes concentration of tension in a laying;

- for architectural reasons laying of interwindow belts on a certain length by height not bandaged with laying piers. This circumstance provokes a warping of sections on border of an interwindow belt and piers in the next zone on height where bandaging is provided;

- lintel in a laying of a obverse layer are presented by combined reinforced concrete crosspiece and the steel corner arranged in obverse exterior tier $120 \mathrm{~mm}$ thick and unprotected outside. Considering an essential difference of coefficients of linear temperature expansion of a laying and steel, it is possible to note that their combined use in one design provokes emergence of cracks and destruction of a laying in a contact zone;

- in deformation seams of the building the laying of obverse layers of bandaging has no.

\section{Description of deformations}

Development of cracks begins in an interwindow belt with the bottom and/or top corner of apertures with a tendency to their merge, including with cracks above - and the below-located interwindow belts, cross-cutting and the trunk (Figure 3).

In bottom corners of apertures of a crack have local sites of an exit to piers; the cracks beginning in the top corners bypassing crossing points, come also to piers. Nevertheless in general, cracks have an obvious vertical focus.

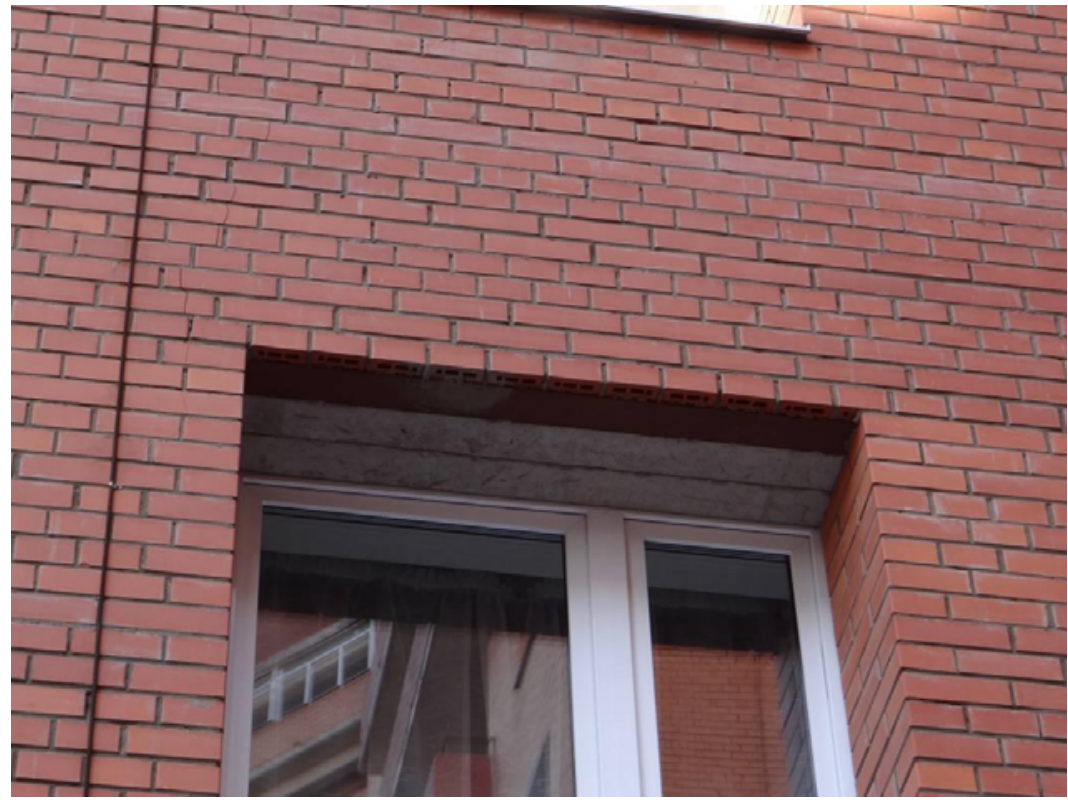

Figure 3. Cracks of vertical orientation on border of interwindow belts and piersu

The width of cracks not more disclosure 2-3 mm. 
It should be noted, that cracks of this type don't prove in interwindow belts which laying isn't bandaged with a laying of piers for architectural reasons.

\section{The results of strength tests}

To determine the actual strength characteristics of a bricklaying from a obverse layer made sampling of brick and mortar, followed by tests in accredited scientific testing laboratory "POLYTECH-SKiMTEST" of the St. Petersburg State Polytechnic University, according to the procedures of state standards (testing brick compressive and bending in accordance with GOST 8462-85, the solution compression in accordance with GOST 5802-86). Results of testing samples of bricks are given in Table 1. The test results of the solution shown in Table 2.

Table 1. Results of tensile strength tests definition bricks flexural and compressive.

\begin{tabular}{|c|c|c|c|c|c|c|}
\hline \multirow[b]{2}{*}{ Marking } & \multicolumn{3}{|c|}{ Compression } & \multicolumn{3}{|c|}{ Bending } \\
\hline & $\begin{array}{c}\text { Breaking load } \\
\text { in compression, } \\
\mathbf{k N}\end{array}$ & $\begin{array}{c}\text { Durability } \\
\text { limit at } \\
\text { compression, } \\
\text { MPa }\end{array}$ & $\begin{array}{c}\text { Average } \\
\text { value of } \\
\text { durability at } \\
\text { compression, } \\
\text { MPa }\end{array}$ & $\begin{array}{l}\text { Breaking } \\
\text { load at a } \\
\text { bend, } k N\end{array}$ & $\begin{array}{c}\text { Durability } \\
\text { limit at a } \\
\text { bend, MPa }\end{array}$ & $\begin{array}{c}\text { Average } \\
\text { value of } \\
\text { durability } \\
\text { at bend, } \\
\text { MPa }\end{array}$ \\
\hline 1 & 172,24 & 12,4 & \multirow{3}{*}{12,8} & 4,16 & 2,46 & \multirow{2}{*}{2,41} \\
\hline 2 & 176,12 & 12,7 & & 4,00 & 2,37 & \\
\hline 3 & 122,75 & 13,4 & & & & \\
\hline
\end{tabular}

Table 2. Test Results Determination of compressive strength solution.

\begin{tabular}{|c|c|c|c|}
\hline $\begin{array}{c}\text { Sample } \\
\text { number }\end{array}$ & $\begin{array}{c}\text { Breaking load, } \\
\text { kN }\end{array}$ & $\begin{array}{c}\text { Durability limit at } \\
\text { compression, MPa }\end{array}$ & $\begin{array}{c}\text { Average value of } \\
\text { durability at } \\
\text { compression, MPa }\end{array}$ \\
\hline 1 & 24,95 & 4,99 & \multirow{2}{*}{4,87} \\
\hline 2 & 27,92 & 5,58 & \multirow{2}{*}{} \\
\hline 3 & 20,20 & 4,04 & \multirow{2}{*}{} \\
\cline { 1 - 3 } & &
\end{tabular}

It may be noted low rates of laying tensile strength, shear and flexural bandaged section. These low levels are not associated with this specific laying, and is characterized in principle for masonry structures (good resistance to compression and low tensile, shear and bending). It is also worth noting the thickness of an obverse layer in $380 \mathrm{~mm}$ and a high voidness brick / stone, which is reflected in the area of cutting and stretching (tensile strength and shear is directly related to the durability characteristics, as well as the cross-sectional area where the efforts of developing countries).

\section{Modeling of structures in the software package Ansys}

In section 5.2 noted that the value of the given plot height of an obverse layer type 2 hred.2 substantially less value given the height of the plot of an obverse layer type 1 hred.1 (hred.2 $<<$ hred.1). An obverse layer pier can also be attributed to the type 2 (with values listed heights respectively hred.1 and hred.2). Considering only the difference of the actual heights of a pier and an interwindow belt, it may be noted that the value of the given height is hred. 3 differ from hred. 1 и hred.2. Difference given heights (hred.1 - hred.3) and (hred.2 - hred.3) leads to a difference of longitudinal deformation and . Bandaging of layings obverse layer of a pier and interwindow beltconstrains noted differences that causes tangent tension, which, given the low resistance of laying shear, leads to warping sections on the boundary layers and cracks (obverse layers are moved relative to each other by their height). Capping model with floor-by-floor support on plates of overlapping in Figure 4, the full height of the building in Figure 5. 


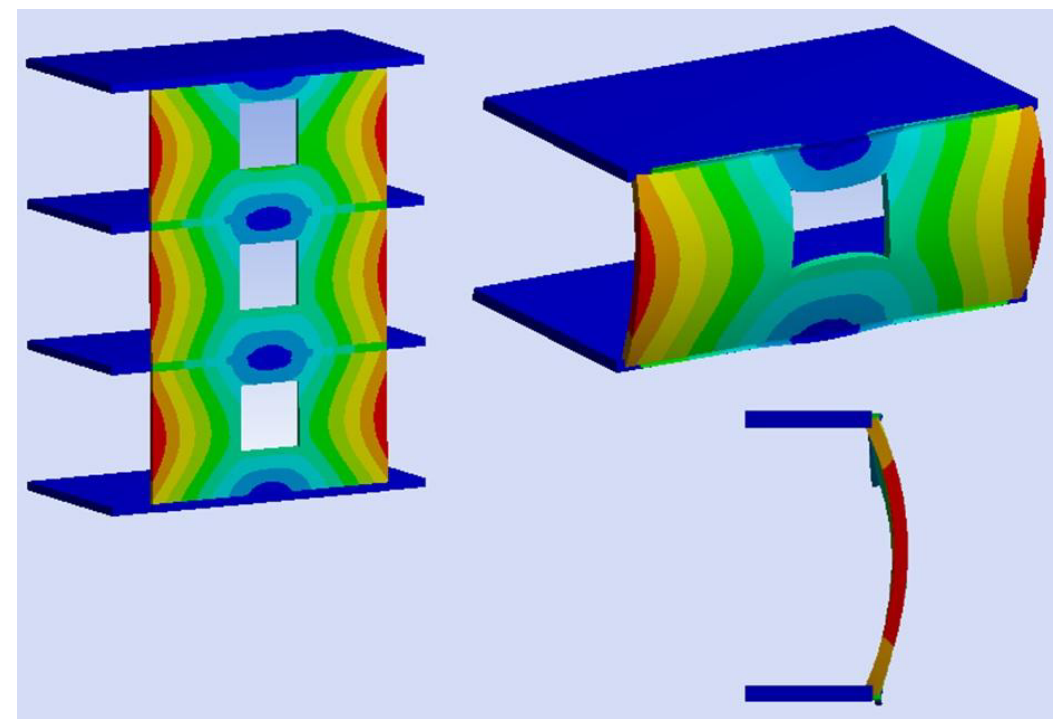

Figure 4. The device of an obverse layer with a floor-by-floor support on overlapping plates

Lack of a horizontal deformation seam between a plate and a laying of an obverse layer, led to that plates put an obverse layer into the general operation of reinforced concrete building structures. At the same time, the corresponding loadings are transmitted through plates on a laying of an obverse layer (the weight of plates, payloads, the load on the balcony fences and etc.). Also we will note that vertical efforts in a laying can arise as from both its own weight of a laying and weight of the designs leaning on it, and from control of temperature influences that finally provoke emergence of cracks.

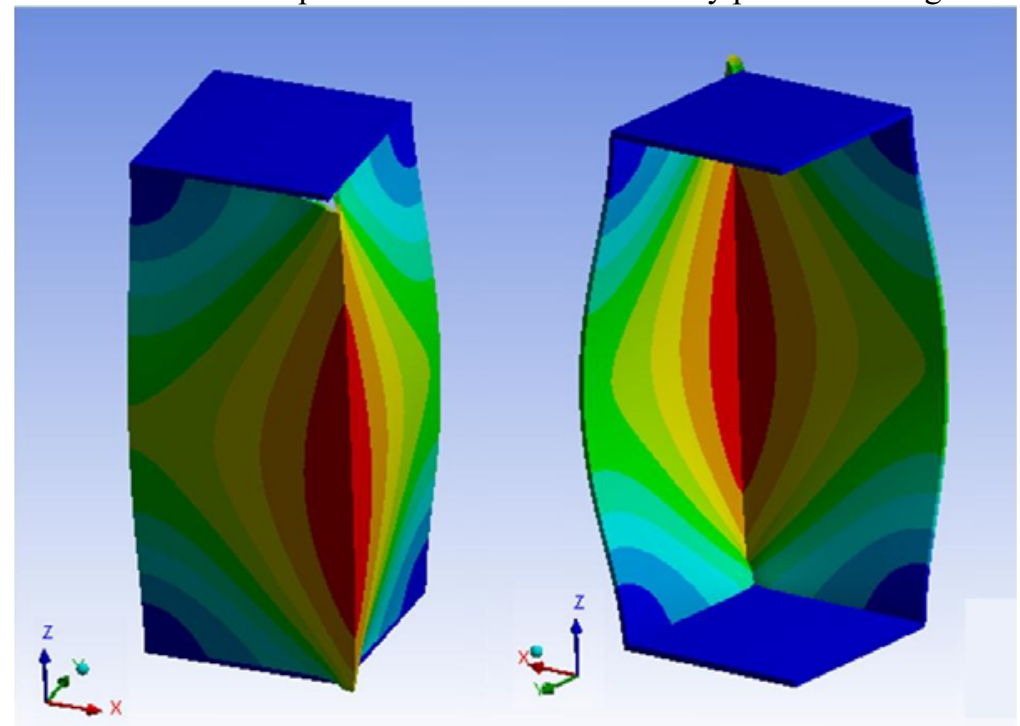

Figure 5. The device of an obverse layer on all height of the building

Thus, these mechanisms also describe the shear adjustment layers, caused by the difference of the longitudinal strain.

However, in this case, it is impossible to call lack of a vertical deformation seam between obverse layers of piers and interwindow belts a background on which these mechanisms prove. Manifestation of mechanisms happens rather against imbalance the rigid of characteristics of communications of interwindow belts and piers concerning deformations of obverse layers. These circumstances caused emergence of vertical cracks on border of interwindow belts and piers. 


\section{Conclusions}

1. The analysis revealed that the main cause of damage to the obverse layer protecting designs is the wrong design.

2. For operational efficiency and durability of the obverse layer sandwich walling should make calculations of a bricklaying shear deformation and temperature, as well as to take into account the difference of temperature deformation of laying and steel lintel.

3. It should be laid in the expansion project of horizontal seams in places of a floor-by-floor support of an obverse layer. It will promote that there was no tension from not projected loadings and flexural deformations.

4. It is necessary to carry out a special calculation of anchors for each floor in places interwindow belts and piers. As a result which does not necessarily have to be identical anchor. The purpose of this calculation must have the same shear strain at each height level.

5. It is not advisable to use a voidness bricks for lining. Since they help to reduce the work anchors due to decrease in the area of friction.

\section{References}

1. A.Y. Naychuk, V.N. Derkach, R.B. Orlovich, Architecture and Constr., 5 (216), 66-68 (2010).

2. M.K. Ishchuk, Construction materials, 10, 87-90 (2008).

3. M.K. Ishchuk, M.V. Shiray, Construction materials, 5, 93-95 (2012).

4. M.K. Ishchuk, A.V. Zuveva, Structural Mechanics and Analysis of Constructions, 4, 71-73 (2006).

5. M.K. Ishchuk, A.V. Zuveva, Industrial and Civil Engineering, 3, 40-43 (2007).

6. M.K. Ishchuk, Housing Construction, 5, 15-19 (2008).

7. M.K. Ishchuk, Housing Construction, 3, 28-31 (2008).

8. M.K. Ishchuk, Construction materials: architecture, 4, 101-105 (2008).

9. M.K. Ishchuk, Housing Construction, 4, 23-27 (2008).

10. M.K. Ishchuk, Integral, 1, 20-22 (2001).

11. M.K. Ishchuk. Technology Building, 2 (64), 28-37 (2009).

12. S.B. Serikkhalivev, S.S. Zimin, R.B. Orlovich, Construction of Unique Buildings and Structures, 5 (20), 28-38 (2014).

13. R.B. Orlovich, N.M. Rubtsov, S.S. Zimin, Magazine of Civil Engineering, 1 (36), 3-11 (2013).

14. S.S. Zimin, N.P. Romanov, O.V. Romanova, Construction of Unique Buildings and Structures, 9 (36), 33-43 (2014).

15. N. Vatin, J. Havula, L. Martikainen, A. Sinelnikov, A. Orlova, S. Salamakhin, Advanced Materials Research, 945-949, 1211-1215 (2014).

16. N. Vatin, J. Havula, L. Martikainen, A. Sinelnikov, L. L. Shurovkina, Applied Mechanics and Materials, 725-726, 722-727 (2015).

17. J.G. Rots, Heron, 3 (2), 49-63 (1991).

18. M. Gilbert, B. Hobbs, C.K. Molvneaux. International journal of impact eng., 3, 253-275 (2002).

19. R. Jasinski, Przeglad Budowlany, 9. 28-36 (2009).

20. K.J. Beasley, The Construction specifier, 2 (51), 25-28 (1998).

21. W. Jager, G. Pfeifer, Mauerwerk Kalender Berlin, 233-264 (2005).

22. M.E. Phipps, T.I. Montague, 7th North American Masonry Conference, 2. 789-798 (1996).

23. N.A. Roumani, The shear strength of prestressed brichwork sections (Ph.D thesis, University of Manchester, 1985).

24. G. Simudic, A.W. Page, 7th North American Masonry Conference, 2,1007-1018 (1996).

25. A. Ponomarev, M. Knežević, N. Vatin, S. Kiski, I. Ageev, Journal of Applied Engineering Science, 12 (3), 227-231 (2014).

26. M. Lazarevska, M. Milanović, M. Knežević, M. Cvetkovska, A.T. Gavriloska, T. Samadzioska, Journal of Applied Engineering Science, 12 (1), 63-68 (2014).

27. B. Š́́epanović, M. Knežević, D. Lučić, O. Mijušković, Proceedings of the 13th East Asia-Pacific Conference on Structural Engineering and Construction, EASEC 2013 (2013).

28. J. Cetkovic, M. Knežević, I. Vujovic, J. Cerovic, Technics Technologies Education Management, 7 (4), 1646-1654 (2012).

29. Z. Radovanović, R. Sinđić Grebović, S. Dimovska, N. Serdar, N. Vatin, V. Murgul, Procedia Engineering, 117, 870-878 (2015). 